\title{
Implementasi Teknik Equivalence Partitioning pada Pengujian Aplikasi E-learning Berbasis Web
}

\author{
Andrian Agustian ${ }^{1}$, Imas Andriyani ${ }^{2}$, Sita Khoerunisa ${ }^{3}$, Adjie Pangestu ${ }^{4}$, Aries Saifudin ${ }^{5}$ \\ Teknik Informatika, Universitas Pamulang, Jl. Raya Puspitek No.46, Buaran, Serpong, Tangerang \\ Selatan, Banten, Indonesia, 15310 \\ E-mail: ${ }^{1}$ andrianagustian1498@ gmail.com, ${ }^{2}$ imasandriyani97@ gmail.com, \\ ${ }^{3}$ sitakhoirunnisa95@gmail.com, ${ }^{4}$ adjiepangestu1397@gmail.com, ${ }^{5}$ aries.saifudin@unpam.ac.id
}

Submitted Date: June $03^{\text {rd }}, 2020$

Revised Date: August 02 $2^{\text {nd }}, 2020$
Reviewed Date: July $26^{\text {th }}, 2020$

Accepted Date: August $03^{\text {rd }}, 2020$

\begin{abstract}
Testing is a verification process carried out to determine the quality of a software. In this case data validation becomes necessary, because errors that occur can make the system not optimal and can harm the owner or user of the system. For example, a compilation error the user can upload any file on the system. This can make the system corrupt and this cannot be known and tested. Black Box Testing has 4 methods, namely Equivalence Partitioning, Pairwise Testing, Boundary Value Analysis and Error Guessing. Each technique has advantages. However, in this study the Equality method was chosen because it was considered the most suitable way to conduct testing on E-learning Applications at Pamulang University. This method returns the system by dividing the input space or range into 2, valid and invalid. Can be obtained trial results obtained. This research begins by determining the functionality that will transfer, determining the data to be contested, determining the input can consist of numerical values, range of values and files, conducting test experiments, documenting research results and repeating results. From the results of tests that have been done, it can be concluded that this device can be used properly and perfectly. However, this research was only carried out using a number of sample forms. For Temporary Devices this can be used properly without any obstacles.
\end{abstract}

Keywords: Testing; Black Box; Equivalence Partitioning; E-learning Application

\section{Abstrak}

Pengujian adalah proses verifikasi yang dilakukan guna mengetahui kualitas sebuah perangkat lunak. Dalam hal ini validasi data menjadi perlu, karena kesalahan yang terjadi dapat membuat kinerja sistem menjadi tidak maksimal dan dapat merugikan pemilik atau pengguna sistem. Contoh, error ketika pengguna dapat mengunggah file apa saja di sistem. Ini bisa membuat sistem menjadi rusak dan hal ini tidak dapat diketahui apabila tidak dilakukan pengujian. Pengujian Black Box memiliki 4 metode, yaitu Equivalence Partitioning, Pairwise Testing, Boundary Value Analysis dan Error Guessing. Masing-masing teknik memiliki keunggulan. Namun, pada penelitian ini dipilih teknik metode Equivalence Partitioning karena dianggap paling sesuai untuk melakukan pengujian pada Aplikasi E-learning di Universitas Pamulang. Metode ini menguji sistem dengan membagi ruang atau jangkauan masukan menjadi 2, valid dan tidak valid. Sehingga test case dapat diperoleh. Alur penelitian ini diawali dengan mengidenifikasi dan menentukan fungsi sistem yang akan diuji, menentukan data dan file yang akan diuji, Perancangan test case, melakukan percobaan pengujian, dan mendokumentasikan hasil penlitian serta penarikan kesimpulan. Dari hasil pengujian yang telah dilakukan, bahwa perangkat lunak ini dapat digunakan dengan baik dan sempurna. Namun, penelitian ini hanya dilakukan dengan menggunakan sejumlah formulir sampel. Untuk sementara perangkat ini dapat digunakan dengan baik tanpa ada hambatan.

Kata Kunci: Pengujian; Black Box; Equivalence Partitioning; Aplikasi E-learning 


\section{Pendahuluan}

Pengujian sistem adalah sesuatu yang harus diperhatikan serta sangat dibutuhkan guna meyakinkan kualitas sistem yang dalam tahap pembuatan ataupun yang sudah ada agar bisa beroperasi fungsinya dengan benar (Ijudin \& Saifudin, 2020). Ini bertujuan untuk memastikan sistem dapat berjalan tanpa ada kesalahan dan sesuai dengan kriteria kebutuhan. Tujuan lain dari dilakukannya pengujian sistem adalah untuk memperoleh produk yang berkualitas yang memberikan produktivitas tinggi (MZ, 2016). Pengujian terhadap perangkat lunak sangat penting dilakukan dengan tujuan untuk memberikan jaminan kualitas perangkat lunak yang dihasilkan agar bebas dari terjadinya kesalahan (Debiyanti, Sutrisna, Budrio, Kamal, \& Yulianti, 2020).

Komputerisasi telah mendominasi di berbagai bidang kerja atau aktifitas untuk meningkatkan kemudahan, efektifas dan efesiensi sehingga memiliki peranan yang sangat penting (Taufiq, Magfiroh, Yusup, \& Yulianti, 2020). Di bidang pendidikan juga telah menerapkan sistem belajar online yang biasa dikenal dengan $e$ learning. E-learning adalah media pembelajaran jarak jauh berbasis teknologi yang disusun berdasarkan prinsip-prinsip dalam proses pembelajaran konvensional (Hernawati \& Aji, 2016). Hal yang membedakan kegiatan pembelajaran e-learning dengan kegiatan pembelajaran konvensional yaitu interaktivitas, kemandirian, dan aksesbilitas (Fransisca, 2017). Metode pembelajaran e-learning dinilai cukup efektif karena dapat diakses dan dipelajari secara mandiri oleh mahasiswa. Jika aplikasi e-learning ini terjadi error akan membuat proses pembelajaran menjadi terhambat, penilaian menjadi tidak maksimal, dan motivasi belajar mahasiswa menjadi menurun.

Untuk permasalahan yang diuji pada penelitian ini adalah masalah validasi data, sebab kesalahan yang terjadi dapat saat proses validasi data memungkinkan seorang pengguna dapat mengunggah file apa saja di sistem. Hal ini menyebabkan kinerja sistem menjadi tidak maksimal dan dapat membuat database sistem menjadi overload.

Metode Pengujian Black Box dengan teknik Equivalence Partitioning merupakan metode terbaik untuk menemukan kesalahan fungsi-fungsi yang hilang atau salah, seperti kesalahan validasi data, kesalahan dalam struktur data atau akses menuju database dan kesalahan performa. Pengujian Black Box dilakukan tanpa harus menguji desain dan kode program untuk mengetahui apakah fungsi, masukan dan keluaran perangkat lunak sesuai dengan spesifikasi yang dibutuhkan (Rahman \& Kurniawan, 2017). Berdasarkan pengujian yang dilakukan maka akan diketahui kelemahan pada sistem informasi setelah dilakukan pengujian menggunakan metode Black Box dengan teknik Equivalence Partitioning dan bagaimana untuk mengetahui hasil yang dianggap valid. Sedangkan untuk tujuan dari pengujian ini adalah mengetahui kelemahan dari sistem agar data yang dihasilkan sesuai dengan data yang dimasukkan setelah data dieksekusi dan menghindari kekurangan dan kesalahan pada aplikasi sebelum digunakan oleh user (Hidayat, 2018).

Berdasarkan kecocokan metode yang digunakan penguji dengan permasalahan yang ada pada sistem, maka dapat dibuat tahapan-tahapan pengujian perangkat lunak berdasarkan metode yang diusulkan. Tahapan-tahapan tersebut yaitu mengidentifikasi dan menentukan fungsi sistem yang akan diuji berdasarkan batas atas dan batas bawah yang diharapkan (Cholifah, Yulianingsih, \& Sagita, 2018).

\section{Metodologi}

Pengujian perangkat lunak memiliki peranan penting dalam pengembangan perangkat lunak, dengan pengujian ini dapat diketahui galat atau error yang akan muncul pada perangkat lunak (Ahrizal, Miftah, Kurniawan, Zaelani, \& Yulianti, 2020). Pengujian sistem bertujuan untuk memastikan apakah tiap proses sudah berfungsi sesuai dengan kebutuhan. Pengujian sistem yaitu suatu proses pelaksanaan program yang bertujuan mengidentifikasi kesalahan dan memperbaikinya sehingga sistem dikatakan layak untuk digunakan (Muslimin, et al., 2020).

Jika suatu test case dapat dikatakan dengan baik yaitu jika test case tersebut dapat menghasilkan suatu kesalahan yang tidak ditemukan diawal. Pengujian yang dilakukan tidak lengkap dan efektif dapat menimbulkan masalah dan menyebabkan kerugian ketika software digunakan (Rosalina, Rassi, Hadi, Ubaidillah, \& Desyani, 2020).

Pengujian memiliki tujuan utama untuk merancang tes dengan cara yang sistematik guna menemukan jenis kesalahan dengan waktu dan usaha yang paling rendah. Pengujian Black Box adalah pengujian yang memfokuskan pengujiannya pada spesifikasi fungsional software yang telah dibuat, sehingga penguji tidak kesulitan untuk 
membuat test case pengujian pada suatu program (Jaya, 2018). Pengujian Black Box yang memiliki arti bahwa pengujian ini hanya memeriksa suatu perangkat lunak dari hasil eksekusinya, tanpa harus tahu mengetahui kode program dan hanya memperhatikan fungsionalnya saja (Nugraha, Aditama, Arrofi, Ahmad, \& Yulianti, 2020).

Dalam penelitian ini akan dilakukan dengan menentukan test case perangkat lunak yang ingin diuji menggunakan teknik Equivalence Partitioning melakukan inisialisasi standar grade partitions masukan dan keluaran. Hal ini dilakukan untuk mendapatkan dataset berupa pengujian menggunakan metode Equivalence Partitioning dan nilai tingkat efektifitas metode Equivalence Partitioning yang telah didokumentasikan. (Kurniawan, Maulana, Sukma, Keumala, \& Saifudin, 2020).

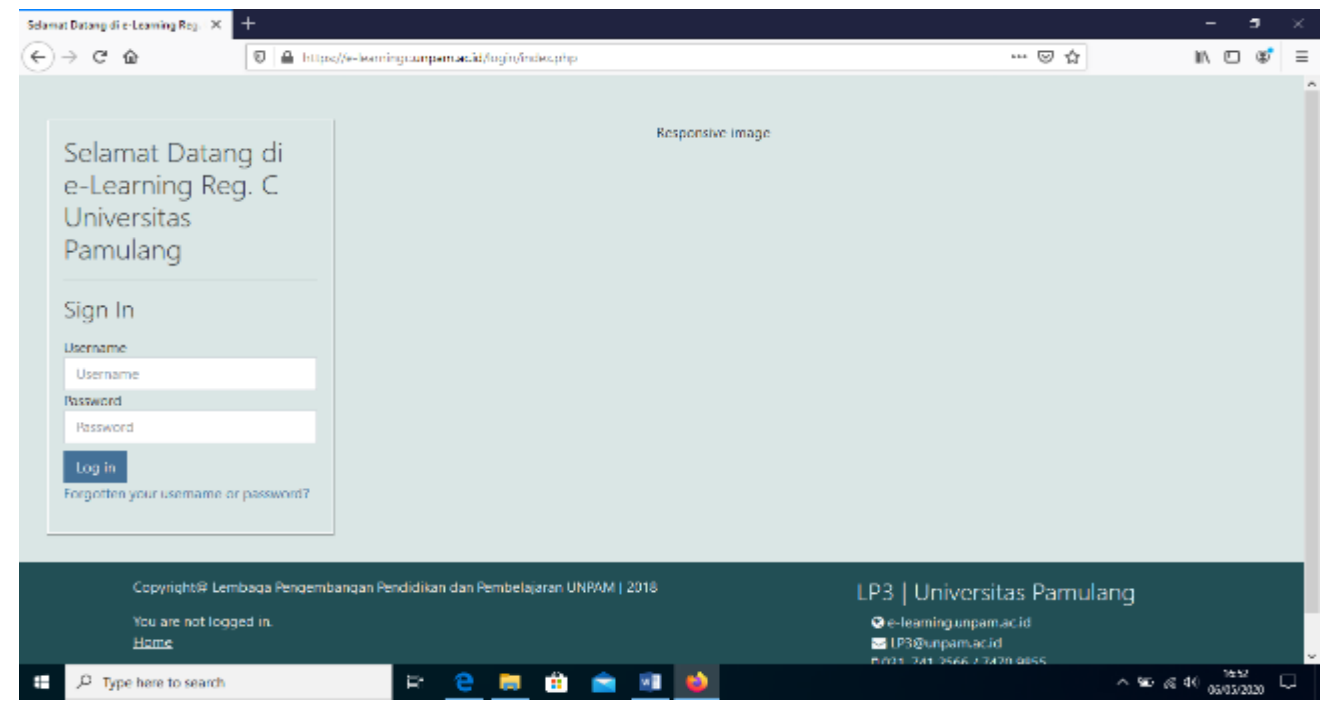

Gambar 1 Form Login

Berdasarkan form pada Gambar 1 terdapat beberapa rencana pengujian. Pada rencana pengujian username akan valid jika diisi dengan memasukkan nim mahasiswa terdaftar (contohnya "2016141188") dengan password tanggal lahir mahasiswa yang bersangkutan("140898"), setelah mengisi form maka Sistem menerima dan menampilkan tampilan dashboard. jika password diisi dengan password yang salah contohnya ("100797") maka sistem akan menolak dan menampilkan pemberitahuan ("Kesalahan ketika login") dan begitu apabila mengosongkan username dan password user akan diarahkan untuk mengisi username dan password.

Table 1 Test Case Form Login

\begin{tabular}{|c|l|l|l|}
\hline ID & \multicolumn{1}{|c|}{ Deskripsi pengujian } & Hasil yang Diharapkan \\
\hline A001 & $\begin{array}{l}\text { Mengisi Username dengan nim mahasiswa terdaftar } \\
\text { "2016141188" dan Password dengan tanggal lahir } \\
\text { mahasiswa tersebut "140898" lalu tekan tombol Log in }\end{array}$ & $\begin{array}{l}\text { Sistem menerima dan user dibawa } \\
\text { masuk ke halaman dashboard }\end{array}$ \\
\hline A002 & $\begin{array}{l}\text { Mengisi Username dengan nim mahasiswa terdaftar } \\
\text { "2016141188" dan Password dengan tanggal lahir } \\
\text { mahasiswa lain "100797" lalu tekan tombol Log in }\end{array}$ & $\begin{array}{l}\text { Sistem akan menolak dan } \\
\text { menampikan notifikasi kesalahan }\end{array}$ \\
\hline A003 & $\begin{array}{l}\text { Tidak mengisi nilai atau input pada Username dan } \\
\text { Password lalu tekan tombol Log in }\end{array}$ & $\begin{array}{l}\text { Sistem akan menolak dan user } \\
\text { diarahkan untuk mengisi } \\
\text { Usename dan Password }\end{array}$ \\
\hline
\end{tabular}

Berdasarkan form pada Gambar 2 terdapat beberapa rencana pengujian. Pengujian unggah file akan valid jika file yang dimasukkan berkapasitas tidak lebih dari $2 \mathrm{MB}$ dan dengan format yang diijinkan oleh sistem. Begitupun sebaliknya file akan tidak valid jika file yang dimasukkan berkapasitas lebih dari $2 \mathrm{MB}$ dan dengan format file yang tidak diijinkan sistem. 


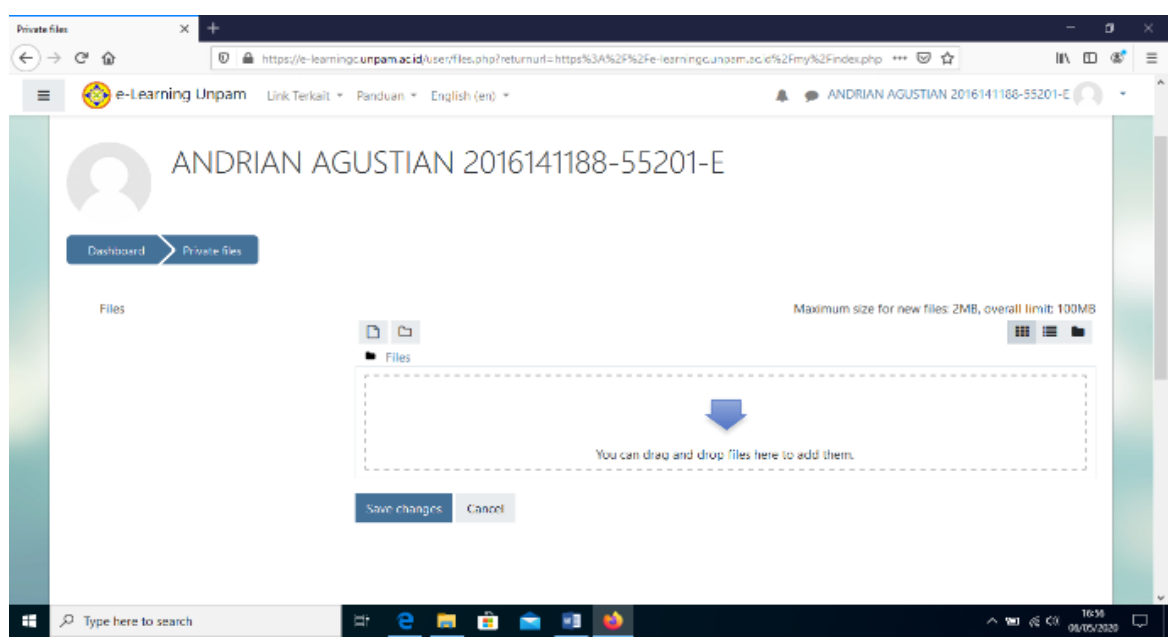

Gambar 2 Form Manage Private File

Table 2 Test Case Form Manage Private File

\begin{tabular}{|c|l|l|}
\hline ID & \multicolumn{1}{|c|}{ Deskripsi pengujian } & \multicolumn{1}{|c|}{ Hasil yang diharapkan } \\
\hline B001 & $\begin{array}{l}\text { Mengunggah file dengan size kurang dari 2 MB dan dengan } \\
\text { format yang diijikan sistem lalu tekan tombol Save Changes }\end{array}$ & $\begin{array}{l}\text { Sistem menerima dan file tersimpan } \\
\text { kemudian file tampil di form } \\
\text { attachment }\end{array}$ \\
\hline B002 & $\begin{array}{l}\text { Mengunggah file dengan size lebih dari 2 MB dengan format } \\
\text { yang diijinkan sistem lalu tekan tombol Save Changes }\end{array}$ & $\begin{array}{l}\text { Sistem menolak dan menampilkan } \\
\text { informasi } \text { error }\end{array}$ \\
\hline B003 & $\begin{array}{l}\text { Mengunggah file dengan size kurang dari 2 MB dan dengan } \\
\text { format yang tidak diijikan sistem ".exe" lalu tekan tombol } \\
\text { Save Changes }\end{array}$ & $\begin{array}{l}\text { Sistem menerima dan file tersimpan } \\
\text { kemudian file tampil di form } \\
\text { attachment }\end{array}$ \\
\hline B004 & $\begin{array}{l}\text { Mengunggah file dengan size lebih dari 2 MB dengan format } \\
\text { yang diijinkan sistem ".exe" lalu tekan tombol Save Changes }\end{array}$ & $\begin{array}{l}\text { Sistem menolak dan menampilkan } \\
\text { informasi } \text { error }\end{array}$ \\
\hline
\end{tabular}

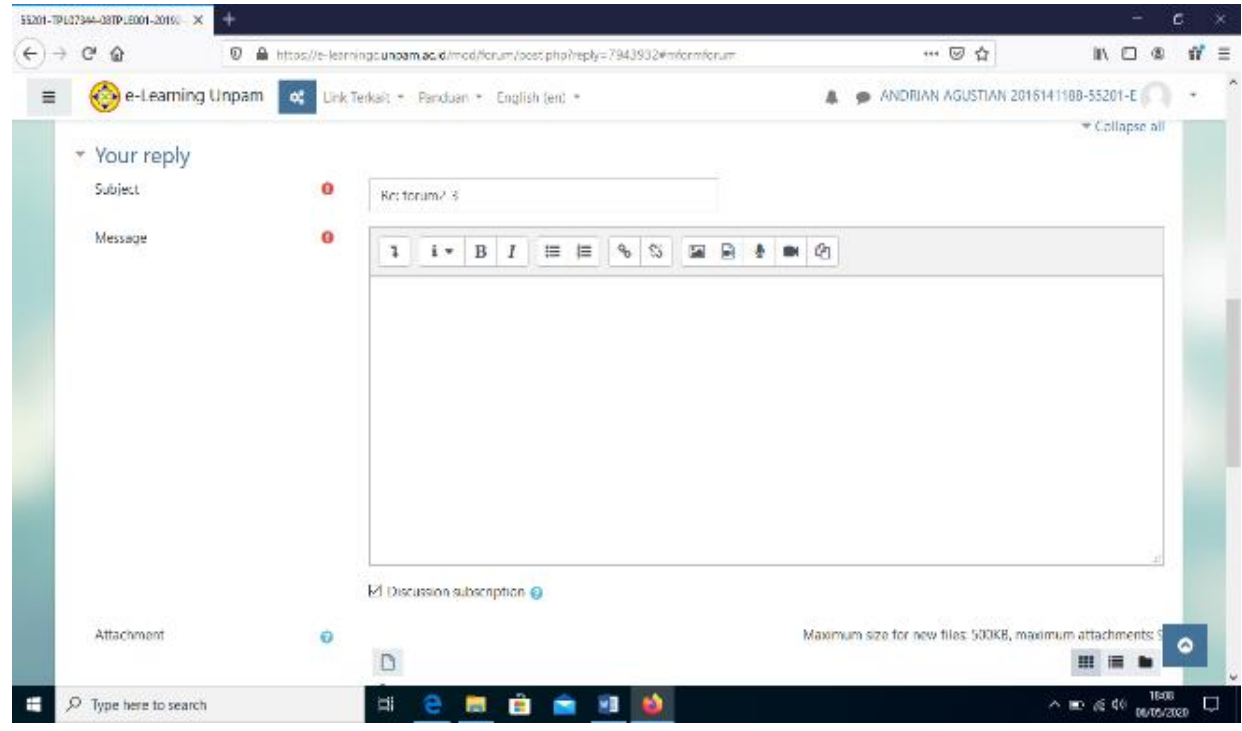

Gambar 3 Form Kolom diskusi 
Berdasarkan form pada Gambar 3. Pengujian text pada kolom diskusi akan valid jika diisi, dan jika dikosongkan sistem akan mengarahkan user untuk mengisi kolom diskusi tersebut.

Table 3 Test Case Form Kolom Diskusi

\begin{tabular}{|c|l|l|}
\hline ID & \multicolumn{1}{|c|}{ Deskripsi pengujian } & \multicolumn{1}{|c|}{ Hasil yang diharapkan } \\
\hline C001 & $\begin{array}{l}\text { Mengisi kolom diskusi dengan Text lalu menekan } \\
\text { tombol post to forum }\end{array}$ & $\begin{array}{l}\text { Teks tersimpan kemudian user dialihkan ke } \\
\text { forum diskusi }\end{array}$ \\
\hline C002 & $\begin{array}{l}\text { Mengosongkan kolom diskusi lalu menekan } \\
\text { tombol post to forum }\end{array}$ & $\begin{array}{l}\text { Sistem menolak dan user diarahkan untuk } \\
\text { menuliskan sesuatu di kolom diskusi }\end{array}$ \\
\hline
\end{tabular}

\section{Hasil dan Pembahasan}

Berdasarkan rancangan kasus uji (test case) yang telah dibuat, dilakukan pengujian dengan metode Equivalence Partitioning. Hasil pengujian didokumentasikan untuk evaluasi dan mengukur nilai tingkat efektifitas metode Equivalence Partitions (Jaya, Gumilang, Wati, Andersen, \& Desyani, 2019). Hasil pengujian yang telah dilakukan ditunjukkan pada Tabel 4.

Table 4 Hasil Pengujian

\begin{tabular}{|c|c|c|c|c|}
\hline ID & Deskripsi Pengujian & $\begin{array}{l}\text { Hasil yang } \\
\text { Diharapkan }\end{array}$ & Hasil Pengujian & Kesimpulan \\
\hline A001 & $\begin{array}{l}\text { Mengisi Username dengan nim } \\
\text { mahasiswa terdaftar "2016141188" } \\
\text { dan Password dengan tanggal lahir } \\
\text { mahasiswa tersebut "140898" lalu } \\
\text { tekan tombol Log in }\end{array}$ & $\begin{array}{l}\text { Sistem menerima dan } \\
\text { user dibawa masuk } \\
\text { kehalaman dashboard }\end{array}$ & $\begin{array}{l}\text { User dibawa masuk } \\
\text { kehalaman dashboard }\end{array}$ & Berhasil \\
\hline A002 & $\begin{array}{l}\text { Mengisi Username dengan nim } \\
\text { mahasiswa terdaftar " } 2016141188 \text { " } \\
\text { dan Password dengan tanggal lahir } \\
\text { mahasiswa lain "100797" lalu tekan } \\
\text { tombol Log in }\end{array}$ & $\begin{array}{l}\text { Sistem akan menolak } \\
\text { dan menampikan } \\
\text { notifikasi kesalahan }\end{array}$ & $\begin{array}{l}\text { Sistem menampikan } \\
\text { notifikasi kesalahan }\end{array}$ & Berhasil \\
\hline A003 & $\begin{array}{l}\text { Tidak mengisi nilai atau input pada } \\
\text { Username dan Password lalu tekan } \\
\text { tombol Log in }\end{array}$ & $\begin{array}{l}\text { Sistem akan menolak } \\
\text { dan user diarahkan } \\
\text { untuk mengisi } \\
\text { Usename dan } \\
\text { Password }\end{array}$ & $\begin{array}{l}\text { User diarahkan untuk } \\
\text { mengisi Usename dan } \\
\text { Password }\end{array}$ & Berhasil \\
\hline B001 & $\begin{array}{l}\text { Mengunggah file dengan size kurang } \\
\text { dari } 2 \mathrm{MB} \text { dan dengan format yang } \\
\text { diujikan sistem lalu tekan tombol } \\
\text { Save Changes }\end{array}$ & $\begin{array}{l}\text { Sistem menerima dan } \\
\text { file tersimpan }\end{array}$ & $\begin{array}{l}\text { File tersimpan, dan } \\
\text { file tampil di form } \\
\text { attachment }\end{array}$ & Berhasil \\
\hline B002 & $\begin{array}{l}\text { Mengunggah file dengan size lebih } \\
\text { dari } 2 \text { MB dengan format yang } \\
\text { diijinkan sistem lalu tekan tombol } \\
\text { Save Changes }\end{array}$ & $\begin{array}{l}\text { Sistem menolak dan } \\
\text { file tidak tersimpan }\end{array}$ & $\begin{array}{l}\text { File tidak tersimpan } \\
\text { dan sistem } \\
\text { menampilkan } \\
\text { informasi error }\end{array}$ & Berhasil \\
\hline B003 & $\begin{array}{l}\text { Mengunggah file dengan size kurang } \\
\text { dari } 2 \text { MB dan dengan format yang } \\
\text { tidak diijikan sistem ".exe" lalu tekan } \\
\text { tombol Save Changes }\end{array}$ & $\begin{array}{l}\text { Sistem menerima dan } \\
\text { file tersimpan }\end{array}$ & $\begin{array}{l}\text { File tersimpan, dan } \\
\text { file tampil di form } \\
\text { attachment }\end{array}$ & Berhasil \\
\hline B004 & $\begin{array}{l}\text { Mengunggah file dengan size lebih } \\
\text { dari } 2 \text { MB dengan format yang } \\
\text { diijinkan sistem ".exe" lalu tekan } \\
\text { tombol Save Changes }\end{array}$ & $\begin{array}{l}\text { Sistem menolak dan } \\
\text { file tidak tersimpan }\end{array}$ & $\begin{array}{l}\text { File tidak tersimpan } \\
\text { dan sistem } \\
\text { menampilkan } \\
\text { informasi error }\end{array}$ & Berhasil \\
\hline $\mathrm{C} 001$ & $\begin{array}{l}\text { Mengisi kolom diskusi dengan Text } \\
\text { lalu menekan tombol post to forum }\end{array}$ & $\begin{array}{l}\text { Teks tersimpan } \\
\text { kemudian user }\end{array}$ & $\begin{array}{l}\text { Teks tersimpan } \\
\text { kemudian user }\end{array}$ & hasil \\
\hline
\end{tabular}




\begin{tabular}{|l|l|l|l|l|}
\hline & & $\begin{array}{l}\text { dialihkan ke forum } \\
\text { diskusi }\end{array}$ & $\begin{array}{l}\text { dialihkan ke forum } \\
\text { diskusi }\end{array}$ & \\
\hline C002 & $\begin{array}{l}\text { Mengosongkan kolom diskusi lalu } \\
\text { menekan tombol post to forum }\end{array}$ & $\begin{array}{l}\text { Sistem menolak dan } \\
\text { user diarahkan untuk } \\
\text { menuliskan sesuatu di } \\
\text { kolom diskusi }\end{array}$ & $\begin{array}{l}\text { User diarahkan untuk } \\
\text { menuliskan sesuatu di } \\
\text { kolom diskusi }\end{array}$ & Berhasil \\
\hline
\end{tabular}

Total pengujian yang dilakukan pada penelitian ini adalah 3 fungsi dengan pengujian login sebanyak 3 kali, fungsi unggah File sebanyak 4 kali, dan fungsi post diskusi sebanyak 2 kali. Dari hasil pengujian yang telah dilakukan, memberikan kesimpulan bahwa perangkat lunak ini dapat digunakan dengan baik dan tidak ditemukan error.

\section{Kesimpulan}

Kesimpulan berdasarkan dari hasil yang didapat ketika menggunakan metode Equivalence Partitioning ini dapat disimpulkan bahwa tekhnik ini yang paling sesuai sebab metode ini menguji sistem dengan membagi ruang menjadi pilihan. Dalam hal ini apabila tidak dilakukan pengujian dapat membuat sistem tidak maksimal dan dalam menentukan tingkat integritas serta kerahasiaan metode lain selain metode Equivalence Partitioning terhadap sistem informasi ini.

\section{Saran}

Aplikasi ini diharapkan dapat dikembangkan agar aplikasi ini dapat memberikan informasi tentang data yang valid seputar nilai. Pengujian juga harus dirancang dengan baik sehingga apabila ditemukan kesalahan bisa diperbaiki dengan singkat.

\section{Referensi}

Ahrizal, D., Miftah, M. K., Kurniawan, R., Zaelani, T., \& Yulianti, Y. (2020). Pengujian Perangkat Lunak Sistem Informasi Peminjaman PlayStation dengan Teknik Boundary Value Analysis Menggunakan Metode Black Box Testing. Jurnal Informatika Universitas Pamulang, 5(1), 73-77. doi:10.32493/informatika.v5i1.4338

Cholifah, W. N., Yulianingsih, \& Sagita, S. M. (2018). Pengujian Black Box Testing Pada Aplikasi Action \& Strategy Berbasis Android Dengan Teknologi Phonegap. Jurnal String Desember 2018, Vol. 3 No.2.

Debiyanti, D., Sutrisna, S., Budrio, B., Kamal, A. K., \& Yulianti, Y. (2020). Pengujian Black Box pada Perangkat Lunak Sistem Penilaian Mahasiswa Menggunakan Teknik Boundary Value Analysis. Jurnal Informatika Universitas Pamulang, 5(2), 162-166. doi:10.32493/informatika.v5i2.5446
Fransisca, M. (2017). Pengujian Validasi Praktikalitas dan Efektivitas Media E-learning di Sekolah Menengah Kejuruan. Jurnal Ilmiah Pendidikan Teknik Elektro, Vol. 2, No.1, 17-22.

Hernawati, E., \& Aji, P. (2016). Perancangan dan Penerapan Konten e-learning melalui Learning Management System dalam Meningkatkan Motivasi Belajar. Journal of Information System Engineering and Business Intelligence, $22-27$.

Hidayat, T. (2018). Pengujian Sistem Informasi Pendaftaran dan Pembayaran Wisuda Online menggunakan Black Box Testing dengan Metode Equivalence Partitioning dan Boundary Value Analysis. Jurnal Teknik Informatika UNIS, 1-5.

Ijudin, A., \& Saifudin, A. (2020). Pengujian Black Box pada Aplikasi Berita Online dengan Menggunakan Metode Boundary Value Analysis. Jurnal Informatika Universitas Pamulang, Vol. 5 (8-12).

Jaya, M. S., Gumilang, P., Wati, T., Andersen, Y. P., \& Desyani, T. (2019). Pengujian Black Box pada Aplikasi Sistem Penunjang Keputusan Seleksi Calon Pegawai Negeri Sipil Menggunakan Teknik Equivalence Partitions. Jurnal Informatika Universitas Pamulang, 4(4), 131136.

Jaya, T. S. (2018). Pengujian Aplikasi dengan Metode Blackbox Testing Boundary Value Analysis. Jurnal Informatika : Jurnal Pengembangan IT (JPIT), Januari 2018, Vol. 03, No. 02.

Kurniawan, A., Maulana, A., Sukma, V. R., Keumala, W., \& Saifudin, A. (2020). Pengujian Black Box pada Aplikasi Penjualan Berbasis Web Menggunakan Metode Equivalents Partitions (Studi Kasus: PT Arap Store). Jurnal Teknologi Sistem Informasi dan Aplikasi, 50-56.

Muslimin, D. B., Kusmanto, D., Amelia, K. F., Ariffin, M. S., Mardiana, S., \& Yulianti. (2020). Pengujian Black Box pada Aplikasi Sistem Informasi Akademik Menggunakan Teknik Equivalence Partitioning. Jurnal Informatika Universitas Pamulang, 5(1), 19-26. doi:10.32493/informatika.v5i1.3778

MZ, M. K. (2016). Pengujan Perangkat Lunak Metode Black-Box Berbasis Equivalence Partitions Pada Aplikasi Sistem Informasi Sekolah. Jurnal Mikrotik Edisi Bulan Februari 2016, Vol.6 No.3.

Nugraha, B. F., Aditama, F., Arrofi, M., Ahmad, S. U., \& Yulianti, Y. (2020). Pengujian Black Box 
pada Aplikasi Penghitungan Parkir Swalayan ADA Menggunakan Teknik Equivalence Partitions. Jurnal Informatika Universitas Pamulang, 5(2), 146-151. doi:10.32493/informatika.v5i2.5350

Rahman, T., \& Kurniawan, D. (2017). Perancangan Pedometer Berbasis Sensor Accelorometer Android. Jurnal Ilmu Pengetahuan dan Teknologi Komputer, Vol. 2, No. 2 Februari 2017.

Rosalina, A., Rassi, A. A., Hadi, G. Y., Ubaidillah, R., \& Desyani, T. (2020). Pengujian Black Box pada Sistem Informasi Penjualan HI Shoe Store Menggunakan Teknik Equivalence Partitions. Jurnal Informatika Universitas Pamulang, 5, 26-29. doi:10.32493/informatika.v5i1.3964

Taufiq, R., Magfiroh, D. A., Yusup, D., \& Yulianti, Y. (2020). Analisis dan Desain Sistem Informasi Pembayaran Sumbangan Pembinaan Pendidikan (SPP) di SMK Avicena Rajeg. Jurnal Teknologi Sistem Informasi dan Aplikasi, $\quad 3(1), \quad 15-21$. doi:10.32493/jtsi.v3i1.4308 